\title{
Estresse ocupacional e o mundo do trabalho atual: repercussões na vida cotidiana das enfermeiras
}

\section{Occupational stress and the current world of the work: repercussions in the nurses' daily life}

\author{
Estrés ocupacional y el mundo del trabajo actual: \\ repercusiones en la vida cotidiana de las enfermeras
}

Sandra Michelle Bessa de Andrade Fernandes', Soraya Maria de Medeiros", Laiane Medeiros Ribeiro"'I

\begin{abstract}
RESUMO
Trata-se de um estudo interpretativo, com abordagem qualitativa, que teve como objetivo analisar as repercussões do estresse ocupacional na vida cotidiana das enfermeiras de uma instituição hospitalar pública, no contexto do mundo do trabalho atual. O marco teórico conceitual foi referente ao mundo do trabalho atual, ao processo de trabalho em saúde e à cotidianidade, a partir dos estudos de Antunes, Mendes Gonçalves e Heller. Utilizou-se como técnica de coleta de informações a história oral temática. O campo de pesquisa foi uma instituição hospitalar pública sediada na cidade de Natal, Estado do Rio Grande do Norte. O período correspondeu ao ano de 2005. A análise das informações foi realizada com base em elementos do método dialético. Os achados apontam que em relação ao fenômeno do estresse ocupacional, as enfermeiras reconheceram a sua existência e a relação do mesmo com o trabalho realizado, definindo-o, principalmente, como a sensação de estar no limite, na iminência do descontrole e como cansaço físico e mental. Conclui-se que o estresse ocupacional decorrente de um processo de trabalho hospitalar, marcado por condições precárias de trabalho e pelo aumento da jornada de trabalho, tem fortes repercussões no cotidiano profissional e pessoal das enfermeiras entrevistadas.
\end{abstract}

Palavras chave: Estresse; Enfermagem do trabalho; Condições de trabalho.

\section{ABSTRACT \\ It is an interpretative study, with qualitative approach, that had as objective to analyze the repercussions of the occupational stress in the nurses' daily life, in a public hospital institution, in the context of the world of the current work. The conceptual theoretical mark was based in the approach social report, focusing the discussion regarding the world of the current}

work, to the work process in health and to the day-to-dayness, starting from Antunes' studies, Mendes Gonçalves and Heller. It was used as technique of information collection the thematic oral history. The survey was conducted in a public hospital placed in Natal city, State of Rio Grande do Norte, during the year of 2005. The analysis of the information was accomplished with base in elements of the dialectic method. The discoveries appear that in relation to the phenomenon of the occupational stress, the nurses recognized their existences and the relationship of the same with the accomplished work, defining it, mainly, as the sensation of being in the limit, in the imminence of the disarray and as physical and mental fatigue. It is concluded that the occupational stress due to a process of hospital work, marked by precarious conditions of work and for the increase of the work day, it has strong repercussions in the daily professional and personal of the interviewed nurses.

Key words: Stress; Occupational health nursing; Working conditions.

\section{RESUMEN}

Este es un estudio interpretativo con abordaje cualitativo que tuvo como objetivo analizar las repercusiones del estrés ocupacional en la vida cotidiana del enfermero en una institución hospitalaria pública, en el contexto del mundo del trabajo actual. El marco teórico conceptual

\footnotetext{
Enfermeira, Mestre em enfermagem pelo Programa de Pósgraduação em Enfermagem da Universidade Federal do Rio Grande do Norte. E-mail: michellebessa@hotmail.com

"Enfermeira, Doutora em enfermagem pela EERP/USP. Coordenadora do Programa de Pós-graduação em Enfermagem da Universidade Federal do Rio Grande do Norte e orientadora da pesquisa. E-mail: sorayamaria@digi.com.br

III Mestranda pelo Programa de Pós-graduação em Enfermagem da Universidade Federal do Rio Grande do Norte.
} 
Fernandes SMBA, Medeiros SM, Ribeiro LM. Estresse ocupacional e o mundo do trabalho atual: repercussões na vida cotidiana das enfermeiras. Revista Eletrônica de Enfermagem [Internet]. 2008;10(2):414-427. Available from: http://www.fen.ufg. br/revista/v10/n2/v10n2a13.htm

fue basado en la discusión referente al mundo del trabajo actual, relacionado al proceso de trabajo en salud y cotidianidad, a partir de los estudios de Antunes, Mendes Gonçalves y Heller. Fue adoptada como técnica de recolección de la información, la historia oral temática. La investigación fue llevada a cabo en un hospital público ubicado en Natal, província de Rio Grande do Norte, en el año de 2005. El análisis de las informaciones fue realizada con base en elementos del método dialéctico. Los hallazgos apuntan que en relación al fenómeno del estrés ocupacional, las enfermeras reconocieron la existencia y la relación de lo

\section{NTRODUÇÃO}

O Mundo atual tem como sinais e emblemas 0 ápice da informatização, o desenvolvimento econômico, as tecnologias de ponta, conformando a chamada era do conhecimento.

Tais mudanças aceleraram o processo de desenvolvimento do chamado fenômeno da globalização, o qual, favorecido pela política neoliberal, deixa de ser mais um conceito para se tornar um modo de produzir e distribuir riquezas, determinando profundas mudanças sobre as condições de vida das populações. Disso decorre uma complexificação dos problemas crônicos da sociedade brasileira, em todos os níveis: social, político, econômico e cultural, com grandes repercussões no âmbito da saúde.

A busca da produtividade a qualquer custo esbarrou nos limites do próprio ser humano e resultou no aumento do seu sofrimento. Esse foi o terreno que propiciou o surgimento da Teoria do Estresse, ou seja, ela nasce no contexto da explosão da produção e do consumo. Embora mudanças substanciais e significativas tenham sido implementadas no mundo do trabalho, com a conquista de avanços tecnológicos significativos, permanecem como desafios a falta de motivação, o desamparo, a desesperança, a passividade, a alienação, a depressão, a fadiga e o estresse ${ }^{(1)}$.

Estudos realizados sobre estresse mostram que apesar de não haver concordância em uma definição clara do que seja estresse, tendo em vista conceitos e concepções diversas sobre o mesmo fenômeno, não se deve mismo en el trabajo realizado, definiendo el estrés como la sensación de estar en el límite, en la inminencia del descontrol y como cansancio físico y mental. Se concluye que el estrés ocupacional se desarrolla en un proceso de trabajo hospitalario, marcado por condiciones precarias de trabajo y por el aumento de la jornada de trabajo, presentando fuertes repercusiones en lo cotidiano de la vida profesional y personal de las enfermeras entrevistadas.

Palabras clave: Estrés; Enfermería del trabajo; Condiciones de trabajo.

discordar totalmente da idéia do estresse como resposta fisiológica ao estressor. Entretanto, é necessário defender a existência de uma reação emocional concomitante às situações que são avaliadas como estressantes, isto é, considerar que a resposta não específica é psicologicamente mediada ${ }^{(2)}$.

Quanto ao estresse ocupacional, percebese igualmente uma extensão da indefinição do conceito de estresse. Considerado pelos pesquisadores como um assunto complexo, o estresse ocupacional não é um fenômeno novo, mas sim um novo campo de estudo que passou a ganhar relevância em conseqüência do aparecimento de doenças que foram vinculadas ao estresse no trabalho, como por exemplo, hipertensão, úlcera, entre outras. Portanto, estresse ocupacional pode ser conceituado como: "conseqüência das relações complexas que se processam entre condições de trabalho, condições externas ao trabalho e características individuais do trabalhador, nas quais as demandas do trabalho excedem as habilidades do trabalhador para enfrentá-las. Provoca conseqüências sob forma de problemas na saúde física e mental e na satisfação no trabalho, comprometendo o indivíduo e as organizações"(2).

O ambiente hospitalar ainda se constitui em uma importante fonte geradora de estresse para os profissionais, principalmente pelo sofrimento vivenciado nesse local. As diferentes situações de trabalho, associadas aos conflitos e aos sentimentos dos trabalhadores, comprometem não só o desempenho produtivo, mas também o equilíbrio físico e emocional 
Fernandes SMBA, Medeiros SM, Ribeiro LM. Estresse ocupacional e o mundo do trabalho atual: repercussões na vida cotidiana das enfermeiras. Revista Eletrônica de Enfermagem [Internet]. 2008;10(2):414-427. Available from: http://www.fen.ufg. br/revista/v10/n2/v10n2a13.htm

desses trabalhadores. Portanto, representa consenso para muitos pesquisadores que a enfermagem é uma profissão estressante, fato que tem estimulado o desenvolvimento de estudos por profissionais, enfermeiros ou não(34).

Para a realização do presente estudo, partiu-se do pressuposto de que a reestruturação produtiva pela qual vem passando o setor de serviços de saúde vem acarretando profundas e significativas mudanças, com repercussões na vida cotidiana da força de trabalho em saúde, particularmente do enfermeiro. As mudanças se apresentam sob a forma da flexibilização das relações trabalhistas, desregulamentação dos direitos sociais e trabalhistas, enxugamento de quadros através de demissões em massa para contenção de despesas, incorporação do subemprego, assim como do regime de trabalho pautado na escala extra e/ou multiemprego, o qual objetiva suprir a deficiência de pessoal, sem a necessidade de realização de concursos e efetivação de quadros, ou seja, explora-se a força de trabalho já existente, mas não se contrata novos trabalhadores, evitando-se dessa forma novos encargos trabalhistas. Dentre as repercussões acarretadas por essas mudanças à vida do trabalhador, destaca-se o estresse ocupacional, desencadeador de danos na esfera do público e do privado na vivência cotidiana desses trabalhadores.

Nesse contexto, foram levantadas as seguintes questões de pesquisa: Quais são os fatores desencadeadores do estresse ocupacional no cotidiano de trabalho do enfermeiro? Quais as formas de manifestações e as características do estresse ocupacional a partir das falas dos enfermeiros? Quais as repercussões produzidas pelo estresse ocupacional na vida cotidiana (esfera do público e do privado) desses enfermeiros?

Com base nestes questionamentos desenvolveu-se 0 presente estudo que tem como objetivo geral: analisar as repercussões do estresse ocupacional na vida cotidiana do enfermeiro, inserido em seu processo de trabalho, em uma instituição hospitalar pública, no contexto do mundo do trabalho atual. Como objetivos específicos: identificar os fatores desencadeadores do estresse ocupacional no cotidiano de trabalho do enfermeiro; conhecer as formas de manifestações e as características do estresse ocupacional a partir das falas dos enfermeiros; conhecer as repercussões produzidas pelo estresse ocupacional, na vida cotidiana (esfera do público e do privado) dos enfermeiros.

\section{METODOLOGI A}

Trata-se de um estudo interpretativo, com abordagem qualitativa, considerando que a mesma trabalha com a profundidade das relações, dos processos e dos fenômenos que não podem ser reduzidos à quantificação ${ }^{(5)}$.

Nesse estudo, entende-se que as repercussões do estresse ocupacional no cotidiano de trabalho do enfermeiro consubstanciam um fenômeno complexo e determinado pelas relações sociais e políticas historicamente construídas na esfera do mundo do trabalho, no âmbito do público e do privado na cotidianidade da práxis do enfermeiro. Desta forma o marco teórico conceitual está embasado, em parte, na abordagem históricosocial, enfocando a discussão referente ao mundo do trabalho atual, o processo de trabalho em saúde e a cotidianidade.

o campo de pesquisa foi uma instituição hospitalar pública estadual, sediada na cidade de Natal, Estado do Rio Grande do Norte, de referência para todo o Estado, integrante do Sistema único de Saúde - SUS, disponibilizando acesso universal para os usuários em todas as faixas etárias. O período para a realização do estudo correspondeu ao ano de 2005.

Antes da entrada em campo, visitou-se o local de pesquisa, explicitando-se os objetivos da pesquisa, que a mesma estava regida pelos preceitos da Resolução 196/96. Em seguida, solicitou-se a autorização para a realização do estudo através de um requerimento que foi assinado pelo diretor geral da instituição e chefia de enfermagem. Posteriormente, o projeto foi enviado para apreciação pelo Comitê de Ética em Pesquisa da UFRN, obtendo aprovação na reunião do dia 03/12/2004 (Protocolo $n^{\circ} 113 / 04$ - CEP).

A população a ser estudada foi escolhida de forma intencional para o alcance dos 
objetivos do estudo; constituíram sujeitos da pesquisa os enfermeiros que atenderam aos critérios de inclusão estabelecidos: enfermeiros com mais de cinco anos de profissão; que atuam ou que já tenham atuado com o regime de dupla jornada de trabalho e, por último, que tenham disponibilidade em participar da pesquisa.

O número total de sujeitos entrevistados foi 15 enfermeiras lotadas em diversos setores do hospital público em estudo. Obedeceu-se ao critério de saturação ou redundância das respostas, como indicativo do momento de parar as entrevistas. As falas dos trabalhadores de enfermagem foram apresentadas com a abreviação Enf ${ }^{a}$ e uma numeração de acordo com a seqüência das entrevistas para assegurar o anonimato.

Utilizou-se como técnica de coleta de informações a história oral temática que consiste em uma forma de coleta de informações baseada no depoimento oral, gravado, obtido através da interação entre o pesquisador e o entrevistado. Nessa técnica, o entrevistado desponta como um ator social, testemunha de fatos relevantes para a compreensão do objeto em estudo, particularmente, para a obtenção de relatos sobre fatos vivenciados na cotidianidade ${ }^{(6)}$.

Como instrumento de coleta de informações, utilizou-se a entrevista individual com roteiros semi-estruturados a partir de questões norteadoras, tendo em vista que a entrevista tem propósitos bem definidos, permitindo colher informações a partir de certos questionamentos básicos, apoiados em teorias e hipóteses do estudo(7).

A análise das informações foi realizada com base em elementos do método dialético, para se buscar a compreensão da realidade estudada. Esse método tem por base a observação da realidade social e sua adequação à visão dialética que privilegia: "a contradição e o conflito predominando sobre a harmonia e o consenso; o fenômeno da transição, da mudança, do vir-a-ser sobre a estabilidade; o movimento histórico; a totalidade e a unidade dos contrários"(5).

Tendo em vista os objetivos propostos no presente estudo e o processo de análise a que foram submetidos os dados, foram geradas três categorias principais: Estressores no cotidiano de trabalho; Concepções acerca do estresse ocupacional; Conseqüências do estresse ocupacional na esfera do público e do privado da vida cotidiana. Vale ressaltar que cada uma dessas grandes categorias foram divididas em subcategorias, que emergiram durante o processo de análise das entrevistas.

\section{RESULTADOS E DISCUSSÃO}

\section{Estressores no cotidiano de trabalho}

Estressor é qualquer situação ou experiência que gera sentimentos de tensão, ansiedade, medo ou ameaça que pode ser de origem interna ou externa ${ }^{(8)}$.

Neste item buscou-se apreender quais eram as situações vivenciadas pelas enfermeiras que representavam estressores, indagando-as sobre quais eram as atividades desenvolvidas pelas mesmas no seu cotidiano de trabalho, que Ihes causavam mais cansaço, ansiedade, tensão, conflito, entre outros. As respostas convergiram para as seguintes categorias: atividades relacionadas à administração de pessoal; a burocracia e a dependência de outros setores; condições de trabalho; jornada de trabalho, trabalho em turnos e sobrecarga de trabalho; pressões, cobranças e carga emocional.

É oportuno destacar que o significado de um estressor é muito singular, uma vez que os indivíduos fazem uma avaliação pessoal de cada vivência, a partir da qual mobilizam recursos pessoais e organizacionais para enfrentar ou superar cada situação estressante vivida. Sendo assim, cada pessoa atribui um significado específico e pessoal para cada situação, cabendo a ela a responsabilidade de avaliar se determinado evento provocou o estresse.

Portanto, as falas explicitadas nas subcategorias a seguir, narram as principais fontes de estresse na concepção das enfermeiras do presente estudo: 
Fernandes SMBA, Medeiros SM, Ribeiro LM. Estresse ocupacional e o mundo do trabalho atual: repercussões na vida cotidiana das enfermeiras. Revista Eletrônica de Enfermagem [Internet]. 2008;10(2):414-427. Available from: http://www.fen.ufg. br/revista/v10/n2/v10n2a13.htm

\section{- Atividades relacionadas administração de pessoal:}

Desde a institucionalização da enfermagem moderna que a execução da atividade administrativa está presente, sendo assim, a dimensão prática das técnicas e a dimensão prática do saber administrativo resultaram na divisão técnica do trabalho na enfermagem, ou seja, alguns agentes administrando e outros executando. A gênese do conhecimento de administração na enfermagem aconteceu junto com a organização das técnicas, sendo as técnicas o instrumento para o cuidado, enquanto o conhecimento de administração foi o instrumento de trabalho para a organização do ambiente terapêutico em que esse cuidado seria realizado. Portanto, a constituição de um saber de administração na enfermagem fez-se urgente pela necessidade de reorganização do espaço hospitalar, sendo em conjunto com as técnicas, o instrumento de trabalho da enfermagem ${ }^{(9)}$.

A atividade que eu acho mais cansativa, por incrível que pareça, não é a prática diária com o paciente, não é isso. [...] Lidar com recursos humanos é o mais cansativo, em termos de você coordenar a equipe quando há um número maior de pacientes, um número mínimo de funcionários, quando há falta de funcionários, aí é um transtorno grande para você cobrir ou ter que dobrar. Você está coordenando isso é o mais cansativo que tem e é o que mais desgasta o processo todo [...] (Enfa 11)

Os achados de um estudo sobre o stress entre enfermeiros hospitalares constatou também que a administração de pessoal é uma área de atuação estressante para os enfermeiros, devido à existência de situações que fogem ao poder de resolução deste profissional e contribuem para a elevação do seu nível de estresse ${ }^{(4)}$.

\section{- A burocracia e a dependência de outros setores:}

Nas falas citadas a seguir, a ênfase foi dada à dependência de outros setores para a realização de atividades, ao estresse ocasionado pela necessidade de esperar que o outro cumpra o seu papel para a partir daí a enfermeira completar o seu processo de trabalho. Sendo assim, as entrevistas analisadas nessa categoria apontam a burocracia como geradora de estresse

Eu acho que a questão burocrática, a questão burocrática ela é muito estressante, mesmo porque envolve outros profissionais, entendeu? $E$ às vezes profissionais que não estão tão comprometidos... e isso causa muito estresse e tensão... A gente às vezes discute entre profissionais tentando resolver uma questão [...].(Enfa 14)

A dificuldade de você conseguir realizar um trabalho que depende de outro setor... um maqueiro... a assistência de um laboratório, uma provisão de material ou de medicamento... O que causa mais estresse na gente é isso. (Enfa 01)

\section{- Condições de trabalho:}

As condições de trabalho englobam tudo que influencia o próprio trabalho. Trata-se não apenas do posto de trabalho e seu ambiente, como também das relações entre produção e salário; duração da jornada; dos horários de trabalho; do repouso e alimentação; entre outras ${ }^{(10)}$.

As falas das enfermeiras entrevistadas deram ênfase às dificuldades decorrentes das precárias condições de trabalho, como por exemplo: A falta de material; $O$ acúmulo de serviços; O volume de trabalho; A polivalência; O ritmo acelerado de trabalho; Recursos humanos inadequados; A necessidade de improvisação na execução de atividades do diaa-dia.

O trabalho, em si, eu não acho estressante. Eu acho estressante as condições de trabalho que a gente é submetido... A falta de material, o acúmulo de serviços, várias funções ao mesmo tempo... Isso é estressante. [...] Me estressa quando eu não tenho material para trabalhar, para fazer determinada atividade, quando eu não tenho funcionário suficiente, quando está muito tumultuado que eu não consigo dar conta do que eu tenho que fazer, isso me estressa. [...] porque você perde muito tempo tentando ver uma maneira, um meio, um caminho de desenvolver uma atividade simples [...] (Enfa 11). 
Fernandes SMBA, Medeiros SM, Ribeiro LM. Estresse ocupacional e o mundo do trabalho atual: repercussões na vida cotidiana das enfermeiras. Revista Eletrônica de Enfermagem [Internet]. 2008;10(2):414-427. Available from: http://www.fen.ufg. br/revista/v10/n2/v10n2a13.htm

Nas falas, as enfermeiras referem-se às precárias condições de trabalho para a realização do seu processo de trabalho. Conforme afirmam, o trabalho não é em si estressante, no entanto, a vivência cotidiana com a falta constante de materiais e recursos humanos, é o que angustia, causando tensão, ansiedade e instabilidade no profissional, que se vê sempre confrontado com situações imprevisíveis que exigem uma capacidade de resolução e improvisação imediatas. Situações que comprometem o processo todo, no momento em que exigem mais atenção e tempo do profissional, atenção essa que poderia está sendo direcionada para a prestação de cuidados diretos aos pacientes e seus familiares e não na improvisação e busca de resoluções para problemas de falta de infra-estrutura e condições de trabalho.

As dificuldades relativas à grande demanda de trabalho e à pouca disponibilidade de recursos materiais e humanos são bem características da área da saúde. O sofrimento deriva da necessidade de ter que ajustar recursos finitos a necessidades de cuidados de saúde infinitas e crescentes por parte da população ${ }^{(11)}$

Estudos realizados anteriormente na mesma instituição mostram nos seus achados que as precárias condições de trabalho, somadas a outros fatores, acarretam desgaste físico, emocional e sofrimento, gerando insatisfação no trabalhador e comprometendo a assistência prestada ${ }^{(12,13)}$.

\section{- Jornada de trabalho, trabalho em turnos e sobrecarga de trabalho:}

Referente ao vínculo empregatício que possuíam e às motivações que levaram-nas a assumi-los, as enfermeiras responderam:

[...] a gente é obrigada pelo momento econômico do país a cumprir mais de uma escala de serviço [...] trabalho em dois hospitais. À manhã eu trabalho aqui e à noite lá. Lá é uma escala bem corrida que eu tenho, é um plantão com folga e outro sem folga. São 12 (doze) ou 13(treze) plantões por mês. Aqui, eu trabalho de segunda à sexta e tenho uma escala corrida de plantão, só que eu tenho extra aqui também de noturno, então eu dou plantão noturno quase todos os dias. Eu dou em torno de 20(vinte) plantões, [...] Eu durmo em casa umas dez noites por mês (Enfa 14).

Os enfermeiros assumem mais de um vínculo empregatício, em conseqüência do baixo nível salarial, objetivando obter melhores condições de vida, porém, acabam por tornarem-se mais cansados e estressados, aumentando a sua vulnerabilidade aos acidentes e causando prejuízos na prestação da assistência à clientela ${ }^{(14,15)}$.

As enfermeiras entrevistadas referiram-se ainda à sobrecarga de trabalho como uma decorrência advinda do excesso de atribuições, ambigüidade ou polivalência de atividades e falta de condições de trabalho. Segundo afirmam a seguir, acabam por desempenhar muitos papéis que não estão previstos no exercício profissional, ou seja, acabam por assumir uma posição de profissional polivalente. O qual deve dar conta de tudo, mesmo sob o desconforto da sobrecarga e da sensação de que está deixando de exercer funções específicas de assistência direta ao paciente, para assumir tarefas diversas no âmbito hospitalar, algo que se soma ao contexto tensiógeno hospitalar e contribui para um agravamento do estresse vivido no cotidiano de trabalho da enfermeira.

[...] Bem, aqui nós somos, é como se a gente fosse um polivalente, de tudo a gente faz um pouco, certo? A gente não atua só como enfermeira não [...] o estresse e o cansaço são muito grandes, devido principalmente ao volume de trabalho. (Enfa 06).

$\mathrm{Eu}$ acho que ocorre sobrecarga porque o enfermeiro apesar de todas as evoluções que houve, ele ainda é muito visto como o que tem que dá conta de tudo, então a gente tem que dá conta da limpeza, tem que dá conta da manutenção, tem que dá conta da enfermagem, tem que dá conta do serviço social, da nutrição, tem que dá conta do material e se você quiser fazer só assistência, não dá! Você tem que se organizar, dentro do seu horário de trabalho, fazer rapidamente. $[\ldots]$, pois as atividades não são bem divididas e é muito sobrecarregado para o enfermeiro. (Enfa 11)

A polivalência aumenta a tensão nervosa e há pessoas que se acabam quando ficam 
Fernandes SMBA, Medeiros SM, Ribeiro LM. Estresse ocupacional e o mundo do trabalho atual: repercussões na vida cotidiana das enfermeiras. Revista Eletrônica de Enfermagem [Internet]. 2008;10(2):414-427. Available from: http://www.fen.ufg. br/revista/v10/n2/v10n2a13.htm

polivalentes, pois o polivalente, embora conheça um grande número de macetes, acumula também zonas de ignorância e, com isso, está confrontado a uma extensão do risco. Cresce o seu medo e pode ocorrer uma descompensação, conduzindo o indivíduo à licença médica, ao repouso forçado ou a um tratamento medicamentoso para depressão(16).

A enfermagem, hoje considerada científica, vive uma "crise" e alguns componentes conhecidos como ameaçadores à estabilidade do enfermeiro são: o número reduzido de enfermeiros na equipe de enfermagem; as dificuldades de delimitar os diferentes papéis entre enfermeiros, técnicos e auxiliares e a falta de reconhecimento nítido entre o público em geral de quem é o enfermeiro ${ }^{(8)}$. Outro agravante que merece atenção é o fato da escala extra não permitir férias ou licença, sendo assim, as enfermeiras que estão com esse regime de trabalho não têm a oportunidade de repousar e desfrutar das férias para repor energias, pois embora tirem férias de uma escala, nunca podem tirar da extra, tendo em vista que, caso isso ocorra, estará fora da extra. Portanto, na fala da Enfa 05, explicitada a seguir, constata-se essa realidade.

$\mathrm{Na}$ escala extra não tem férias, você entra de férias de uma escala e continua dando a extra, mas aí esse ano as minhas férias estão mercadas para julho e eu já estou conseguindo arranjar uma pessoa para pagar, para dar esses plantões, acho que depois de 10 (dez) anos eu vou ter férias. Não tem dez anos que tem extra, mas era de outras pessoas que eu trabalhava nas férias, eu tirava férias e pegava outras escalas e, isso, porque o poder aquisitivo da gente caiu muito, má remuneração. Então, para manter você com filho em colégio, enfim, a condição mínima de moradia, saúde, educação para os filhos, você tem que ter essa sobrecarga e se a mulher for só, como eu que sou pai e mãe, aí nesse sentido pega mais. (Enfa 05).

Um estudo realizado sobre o estresse do enfermeiro com dupla jornada de trabalho, traz a discussão das conseqüências dos múltiplos papéis assumidos pelas mulheres que exercem uma atividade profissional. Essas mulheres tendem a se sentir impotentes e frustradas por não conseguirem conciliar seus inúmeros afazeres, a sobrecarga de trabalho com as duplas ou triplas jornadas pode conduzir ao estresse, devido ao acúmulo de atribuições, tendo em vista que sua inserção no mercado de trabalho não as desvinculou das tarefas domésticas e da educação dos filhos ${ }^{(17)}$.

\section{- Pressões, cobranças e carga emocional:}

Essa subcategoria refere-se às situações recebidas que chegam como pressões para o cumprimento dos seus deveres, as quais muitas vezes se fazem impossíveis devido a fatores diversos, representam ainda as exigências para que outros cumpram com suas obrigações, ou seja, da mesma forma que recebem cobranças igualmente tem que exercê-las ${ }^{(8)}$.

$\mathrm{Na}$ instituição tem essa hierarquia toda, da opressão da diretoria e a gente é muito cobrada e a gente tem que cobrar do auxiliar, é um chicote, um em cima do outro, um na gente e outro no auxiliar. [...] (Enfa 05).

[...] às vezes você fica muito estressada porque são muitos pedidos, muitas cobranças, o médico Ihe cobra, o acompanhante lhe cobra, você se cobra também, o técnico lhe cobra, então são muitas cobranças e você fica muito cansada, estressada, sem paciência, não é? (Enfa 10).

O poder decisório da enfermagem é pequeno, dependente de outros setores, e suas possibilidades de ação são dependentes das regras de funcionamento da instituição. Portanto, nas falas das enfermeiras supracitadas, percebe-se claramente as pressões e as cobranças vivenciadas cotidianamente no hospital em estudo.

Um estudo que abordou, dentre outros pontos, o nível de estresse em enfermeiros de unidades abertas e fechadas de uma instituição hospitalar e os estressores presentes no ambiente de trabalho, encontrou como conclusão que todas as áreas de atuação do enfermeiro pesquisadas foram consideradas estressantes. Os principais estressores encontrados para enfermeiros de unidades abertas foram agrupados nas seguintes áreas: Relacionamento com outras unidades e supervisores; Assistência de enfermagem 
Fernandes SMBA, Medeiros SM, Ribeiro LM. Estresse ocupacional e o mundo do trabalho atual: repercussões na vida cotidiana das enfermeiras. Revista Eletrônica de Enfermagem [Internet]. 2008;10(2):414-427. Available from: http://www.fen.ufg. br/revista/v10/n2/v10n2a13.htm

prestada ao paciente; Coordenação das atividades da unidade; Condições de trabalho para o desempenho das atividades do enfermeiro. Os estressores encontrados para enfermeiros de unidades fechadas foram englobados na área: atividades relacionadas ao funcionamento adequado da unidade. $O$ estudo identificou os estressores agrupados na área atividades relacionadas à administração de pessoal, em ambas as áreas ${ }^{(4)}$.

\section{Concepções acerca do estresse ocupacional}

Quando perguntadas sobre o que entendiam por estresse, as enfermeiras não explicitaram claramente um conceito, porém descreveram os fatores e situações que levam ao estresse, as suas causas e, principalmente, o que resulta a partir do estresse, as conseqüências, corroborando as dimensões apontadas nos estudos que referenciam a presente pesquisa.

Portanto, ao definirem 0 estresse ocupacional, as falas das enfermeiras entrevistadas convergiram para as seguintes subcategorias temáticas: É estar no limite... Estar na iminência do descontrole; Tratar mal as pessoas... Quando o espelho olha para si mesmo; Quando não consigo conciliar as atividades exigidas pelo cotidiano; O cansaço físico e mental.

\section{- É estar no limite... Estar na} iminência do descontrole:

Na fala da Enfa 05 a seguir o estresse é abordado como sobrecarga de trabalho: algo que exige em excesso do trabalhador e que leva à sensação de estar no limite de uma somatória de situações estressantes, tendo como desdobramentos o cansaço e a falta de paciência.

Estresse... estresse é uma sobrecarga... Eu sinto, assim, uma sobrecarga muito grande, onde você sente como se estivesse no limite de uma série de sinais e sintomas, você sente cansaço, a falta de paciência no lidar com o paciente. Tem momentos que você precisa recuar... Sair lá para o posto, se trancar um pouquinho... Estresse é esse limite, de uma somatória de situações estressantes (Enfạ 05).
O momento em que se percebe que se pode extrapolar o normal, sair da rotina, é detectado também pelas enfermeiras como chegar ao limite. Esse limite que não deve ser ultrapassado é compreendido como sinais de alerta bem definidos e identificados pelas enfermeiras em suas falas, tais como quando começam a perceber que estão respondendo de forma grosseira e/ou tratando mal os pacientes, entre outros. Esse risco que tem como sinal de alerta o momento que as enfermeiras passam a tratar mal as pessoas, pode ser vislumbrado no compasso da rotina cotidiana.

\section{- Tratar mal as pessoas... Quando o espelho olha para si mesmo:}

Nas narrativas a seguir, constata-se uma semelhança no discurso referente ao descontrole emocional, sob a forma de agressividade, assim como uma autoconsciência das enfermeiras, que reconhecem o quanto esse descontrole é desagradável e prejudicial, posto que, embora consigam controlarem-se na relação com o paciente, o mesmo não acontece no convívio familiar.

Acho que estresse é quando realmente você não está bem com você e você se irrita facilmente, trata mal as pessoas que não merecem ser tratadas. Eu tento muito, muito mesmo, controlar esse momento meu. Às vezes eu faço uma coisa errada, eu compreendo que faço errado, porque eu não faço esse tipo de tratamento nem com funcionários, nem com pacientes, mas em compensação, às vezes eu passo isso em casa com minhas filhas, com meu marido. Sei que estou errada, mas acho que eles conseguem me entender mais que os pacientes e funcionários (Enfa 07).

O que se pode apreender dessas falas é um sentimento muito forte de reflexão sobre a própria condição humana como ser, na vivência cotidiana, seus valores, suas crenças, seus afetos: como se fosse um espelho olhando para si mesmo, com suas multifaces e interfaces.

É o cansaço físico e mental que dá na gente e não vale a pena você colocar para outras pessoas que estão com a gente trabalhando, de você estourar com essas pessoas, porque às vezes acontece, não é? De você ir acumulando 
Fernandes SMBA, Medeiros SM, Ribeiro LM. Estresse ocupacional e o mundo do trabalho atual: repercussões na vida cotidiana das enfermeiras. Revista Eletrônica de Enfermagem [Internet]. 2008;10(2):414-427. Available from: http://www.fen.ufg. br/revista/v10/n2/v10n2a13.htm

e, quando você coloca para fora, é justamente isso, o cansaço (Enfa 13 ).

Percebe-se ao longo dessas duas narrativas uma semelhança no discurso, referente ao descontrole emocional, sob a forma de agressividade, assim como a auto consciência das enfermeiras, que reconhecem o quanto isso é desagradável e prejudicial e que embora consigam se controlar em relação ao paciente, procurando não demonstrar ou tratálos de forma agressiva, acabam por extravasar com a família e filhos.

\section{- Quando não consigo conciliar as atividades exigidas pelo cotidiano:}

As dificuldades de corresponder às exigências impostas pelo cotidiano de trabalho, nas quais o ritmo acelerado e a sobrecarga se destacam e, ao mesmo tempo, conciliar essas exigências com as dimensões do mundo privado, tais como a convivência familiar e as demandas subjetivas do exercício da individualidade, constituem-se como uma queixa e um sinal emblemático da complexidade do cotidiano das enfermeiras entrevistadas: conceito e tradução de uma vivência cotidiana.

Eu acho que estresse é quando você apresenta, assim, eu acho que você fica muito cansado para exercer qualquer atividade e você não consegue coordenar as atividades que você tem, quando você não consegue dar conta das atividades que você tem para fazer, dentro de casa, fora de casa ou no trabalho... Aí causa aquele sentimento de angústia. Eu acho que, para mim, isso é estresse (Enfa 11).

Na fala da Enfa 11, embora a mesma não tenha tratado do que pode vir a causar esse cansaço que a impede de realizar qualquer atividade, a entrevistada detém-se na narrativa das conseqüências do estresse na vida cotidiana, especialmente quando afirma: "você não consegue coordenar as atividades que você tem, quando você não consegue dar conta das atividades que você tem para fazer, dentro de casa, fora de casa ou no trabalho...", referindose ainda a uma conseqüência de ordem psíquica, no caso, a angústia.

A angústia nesse contexto do estudo é compreendida como conseqüência da opressão e sofrimento vivenciado no cotidiano de trabalho. Essa opressão e sofrimento são resultantes das exigências da organização do trabalho em desacordo com as necessidades e desejos do trabalhador, esse desacordo causa a desadaptação do trabalhador ${ }^{(15)}$.

\section{- O cansaço físico e mental:}

No conceito de Swan, Moraes e Cooper ${ }^{(2)}$, o estresse é entendido como um problema negativo, de natureza perceptiva, resultado da incapacidade de lidar com as fontes de pressão no trabalho, provocando conseqüências sob a forma de problemas na saúde física e mental e na satisfação no trabalho, comprometendo os indivíduos e as organizações. Nesse contexto, o cansaço físico e mental é abordado neste item com as falas das enfermeiras.

Estresse é o cansaço, porque a mente, o que influencia muito é a nossa mente, por isso que eu procuro pagar dois finais de semana, porque justamente eu acho que na sexta feira, tem semanas, que a gente já chega nas últimas, no limite, então é muito estressante, é muito cansativo. É o cansaço físico e mental que dá na gente e não vale a pena você colocar para outras pessoas que estão com a gente trabalhando, de você estourar com essas pessoas, porque às vezes acontece, não é? De você ir acumulando e, quando você coloca para fora, é justamente isso, o cansaço (Enfa 13).

A fala da Enfa 13 traz a questão do cansaço, que é uma conseqüência do estresse e faz referência ao fato de pagar dois plantões, ou seja, daí infere-se que o estressor carga horária de trabalho, da categoria (fatores intrínsecos ao trabalho), fez-se presente no desencadear do estresse, levando ao cansaço físico e mental que leva, conseqüentemente, o indivíduo ao descontrole, descontrole esse explicitado na fala da enfermeira como o acúmulo desse cansaço.

Portanto, apesar das enfermeiras não definirem claramente estresse, referem-se às suas causas e, principalmente, às suas conseqüências, estando em consonância com as definições de estresse ocupacional adotadas nesse estudo.

Pesquisas sugerem que fatores estressores e específicos do trabalho, como: o clima de trabalho negativo, papéis ambíguos, a falta de clareza nas tarefas executadas, 
Fernandes SMBA, Medeiros SM, Ribeiro LM. Estresse ocupacional e o mundo do trabalho atual: repercussões na vida cotidiana das enfermeiras. Revista Eletrônica de Enfermagem [Internet]. 2008;10(2):414-427. Available from: http://www.fen.ufg. br/revista/v10/n2/v10n2a13.htm

expectativas não alcançadas, a sobrecarga de trabalho, têm efeitos adversos na saúde dos trabalhadores contribuindo para o surgimento do estresse e, consequentemente, o deterioramento da saúde mental ${ }^{(18)}$.

\section{Consequências do estresse ocupacional na esfera do público e do privado da vida cotidiana}

A vida cotidiana é a vida do homem inteiro, não existindo homem sem cotidiano e cotidianidade, o homem participa da vida cotidiana com todos os aspectos de sua individualidade, de sua personalidade. Entretanto, a vida cotidiana não se reduz a "usos e costumes", nem a "casa e quarto" ou ao "rotineiro e repetitivo", tendo em vista que a história é vivida e, em primeira instância, decifrada no cotidiano. De modo algum o cotidiano pode ser confundido com as rotinas e banalidades de todos os dias. Os momentos da vida cotidiana e os espaços são no público e no privado, ou seja, em casa, mas também na rua e no local de trabalho ${ }^{(19)}$.

$$
\text { Quando perguntadas quais as }
$$

conseqüências do estresse na sua vida cotidiana, consigo mesma, com a família, no trabalho com os colegas e com os doentes, as enfermeiras responderam que:

\section{- Quanto à esfera do privado: relação consigo mesma.}

A irritação, o cansaço, o sono acumulado, - desânimo e a diminuição das defesas imunológicas são marcas de uma trajetória cotidiana que se renova e se acumula na ciranda das excessivas jornadas de trabalho das enfermeiras entrevistadas.

[...] Eu fico muito irritada, isso é uma coisa constatada mesmo, eu percebo que eu fico muito irritada, o sono começa, por conta que eu trabalho também à noite, o sono fica muito comprometido. Eu faço terapia já há cinco anos, porque uma das minhas queixas para fazer terapia é porque eu notava que o estresse do hospital estava acarretando muito dificuldade de eu lidar com os colegas, com os pacientes, com o meu filho, enfim, a minha vida pessoal começava a complicar também porque eu estava muito estressada [...] eu sou muito estressada e tem horas que isso reflete na mente, no físico e em tudo, não é? (Enfạ 05).

Comigo mesma, o que acontece é que como eu tenho uma carga grande de trabalho, eu tenho que me cuidar, porque uma gripe - uma gripe assim - me deixa bem abatida [...]. (Enfa 10).

O sentimento de impotência está presente nas falas das enfermeiras de forma explícita, como no relato da Enfa 11 citado a seguir, ou de forma implícita quando as entrevistadas falam sobre o desânimo, a incapacidade de resolver coisas, a angústia e o cansaço, entre outros.

Eu acho que o pior é com a gente mesmo, porque gera um sentimento de angústia muito grande, de incapacidade de você resolver as coisas [...] Acho que o pior é com a gente mesmo... A gente fica bem insatisfeita com o que a gente está fazendo, porque você não está fazendo o que você quer... você está fazendo o que você pode fazer naquele momento, mas deixa a desejar, você fica com aquele sentimento de... você fica com o sentimento de impotência. É a sensação de que o processo de trabalho não se completou por coisas banais. (Enfa 11).

Segundo(11), a exposição a longas jornadas de trabalho, a precarização das relações de trabalho, a desvalorização salarial, as graves deficiências nas condições de trabalho, desencadeiam além de processos físicos e emocionais, sentimentos que revelam trabalhadores com a auto-estima em queda. Essa relação de aviltamento à sobrevivência humana é evidente e se encaminha para o entorpecimento da sua dimensão humana, depressão, alienação, entre outros.

Outro aspecto de destaque nas falas das enfermeiras é a queixa sobre a falta de tempo: falta de tempo para si mesma, para o exercício da subjetividade, o lazer, as várias formas de aprendizado e o próprio cuidado consigo mesma, particularmente o cuidado com a sua saúde.

Falta de tempo para casa, para mim mesma, não é? Porque para ir para o médico eu tenho que marcar, agendar naquele dia, às vezes só tem uma vaguinha daqui a quinze dias, vinte dias, entendeu? Eu estou com uns exames para fazer de rotina, do cardiologista, mas estou sem tempo de marcar os exames, entendeu? Porque 
Fernandes SMBA, Medeiros SM, Ribeiro LM. Estresse ocupacional e o mundo do trabalho atual: repercussões na vida cotidiana das enfermeiras. Revista Eletrônica de Enfermagem [Internet]. 2008;10(2):414-427. Available from: http://www.fen.ufg. br/revista/v10/n2/v10n2a13.htm

é no meu horário de trabalho e eu não quero faltar o meu trabalho para fazer um exame, não é? Eu quero ver se eu consigo pagar um plantão, adaptar o horário do exame ao meu horário de folga. (Enfa 14).

\section{- Quanto à esfera do privado: relação com a família.}

As queixas e os exemplos de conflitos e sofrimentos advindos dos mesmos, na relação familiar, são muito presentes nas falas das enfermeiras, desdobrando-se em sentimentos de solidão, angústia, incompreensão, irritação, cansaço, entre outros.

Com a família também, porque quando você está estressada, a primeira coisa que vem e que realmente é acometida é a família. Você já deixa de dar aquela assistência legal, aquele carinho, você já grita "sai para lá menino, eu estou cansada", não é? (Enfa 02).

Olha, com a família porque eu chego às vezes em casa sem querer falar, sabe? Sabe quando você não quer escutar nem barulho? Geralmente é assim. (Enfa 04).

Nas falas das enfermeiras 02 e 04, constata-se a irritação pelo cansaço.

Esse cansaço parece que imprime um ritmo tão lento que a narrativa das vidas dessas enfermeiras é expressa em uns ângulos como um filme em câmara lenta e em outros como um filme mudo com rotação acelerada, outros como um filme sem falas com ambientação de um tempo passado em tons desbotados e com som melancólico de música ao longe.

Família eu acho que sente muito, porque você passa mais tempo fora, você cuida mais dos outros do que de você e da sua família, porque o seu tempo está mais para o trabalho, então você acaba esquecendo de você e da família, e isso é uma coisa séria. (Enfa 10).

Olha, as conseqüências é isso que eu digo para você, você não consegue, por exemplo, ter o seu lado social, porque na hora que você chega em casa, se você tem um convite para ir... você pensa em quê? Você pensa no cansaço, "amanhã eu vou dar plantão novamente", "o meu setor está cheio, amanhã eu tenho que está logo cedo lá" Então, você vai abdicando um pouco do seu lazer, eu acho que é uma conseqüência que não é muito boa, eu sinto muito isso na minha família. Porque, por exemplo, meus filhos querem lazer, no dia que eu estou de folga fica difícil para mim, às vezes eu tenho que ir para fazer o lazer com eles, fazer o gosto deles porque eu preciso, eu sou mãe, mas muitas vezes você não vai satisfeita porque você está cansada e queria está dormindo, isso é uma conseqüência muito ruim para a família. (Enfa 12).

Esse cansaço muitas vezes se traduz por irritação e/ou agressividade, como se constata na fala a seguir:

[...] Traz, não traz danos maiores, porque como eu já reconheço que isso é ruim para a gente, profissional e pessoal, aí eu faço terapia, consegui me trabalhar quanto a isso, mas pagando um ônus alto. Além do tempo fora de casa, o ônus pessoal de relação com a família e o ônus financeiro, porque terapia é muito caro... [...] Eu tenho um filho e ele reclamava que eu estava gritando muito com ele. (Enfa 05).

Outro aspecto vislumbrado nas narrativas dessas enfermeiras é o sentimento de solidão e vazio existencial: uma solidão que parece sofrer por ver-se e ter consciência da condição dessa cotidianidade marcada pelo trabalho solitário de um trabalhador em processo de produção coletiva. O descompasso com o ritmo da família, traz o sentimento de ausência de um lugar, um papel social não exercido, enfim, vazio e silêncio.

Por outro lado, em alguns momentos nas falas das enfermeiras entrevistadas, percebe-se a tentativa de "compensação" e/ou "superação" desse cotidiano de fadiga e cansaço, através da adoção de estratégias como a separação entre a vivência no trabalho e o convívio familiar.

Eu procuro não misturar, por exemplo, eu procuro não levar esses problemas, esses estresses de coisas que não consegui realizar, eu procuro deixar aqui para não levar para casa, descarregar na família, eu acho que não é por aí, não é? [...] o meu menino reclama, ele sente muito a minha falta porque é o menor, por isso eu procuro quando estou em casa dá tudo de mim pra eles, procuro aproveitar os momentos, sabe? (Enfa 13).

Não, quando eu saio daqui, eu não levo mais estresse para casa, não, eu já deixo e lá é outro clima. Eu não levo essa preocupação para casa, 
Fernandes SMBA, Medeiros SM, Ribeiro LM. Estresse ocupacional e o mundo do trabalho atual: repercussões na vida cotidiana das enfermeiras. Revista Eletrônica de Enfermagem [Internet]. 2008;10(2):414-427. Available from: http://www.fen.ufg. br/revista/v10/n2/v10n2a13.htm

não. Lá eu tenho outro ambiente e nunca, assim, eu fiquei estressada em casa por causa de coisas do trabalho e vice-versa (Enfa 03 ).

\section{- Quanto à esfera do público: relação com os colegas de trabalho.}

Nas falas as enfermeiras quando abordam a questão da relação interpessoal com a equipe multiprofissional e/ou equipe de enfermagem, constata-se a existência de conflitos, cobranças, incompreensões e insensibilidades.

As conseqüências... é... As conseqüências às vezes deixam esse estresse... Às vezes a gente chega mais calma, às vezes perde a paciência [riso] com o colega, às vezes é com o doente, o doente com a gente e assim vai [...] O colega às vezes está estressado e o outro não entende, não é? Acha que é porque não quer fazer isso ou aquilo, ou porque está se escorando. Às vezes a gente não tem nem tempo de falar de si mesmo, o seu colega jamais vai adivinhar o que você está passando porque você não tem letreiro na testa, não é? Eu sei que a gente não pode trazer os problemas de casa para cá, mas você é gente cuidando de gente, não é? Então às vezes a gente não consegue assimilar isso, aí diz às vezes piada ou escuta, sabe? De vez em quando acontece uma coisa dessas e às vezes tem uma conseqüência para a gente meio chata... Mas é isso mesmo... é ser humano, não é? (Enfa 08)

Uma vida cheia de sentido em todas as esferas do ser social, dada pela omnilateralidade humana, somente poderá efetivar-se por meio da demolição das barreiras existentes entre tempo de trabalho e tempo de não trabalho, de modo que, a partir de uma atividade vital cheia de sentido, autodeterminada, para além da divisão hierárquica que subordina o trabalho ao capital hoje vigente e, portanto, sob bases inteiramente novas, possa se desenvolver uma nova sociabilidade ${ }^{(20)}$.

\section{- Quanto à esfera do público: relação com os pacientes.}

Indagadas sobre a repercussão do estresse no cotidiano de trabalho na relação com os pacientes, as enfermeiras entrevistadas expressaram muito fortemente o sentimento de cuidado nessa relação.

O paciente na fala dessas enfermeiras é o outro, a alteridade por excelência, é o ser outorgado como interlocutor, porque se constata que é com e para ele que essas enfermeiras voltam os seus olhares: é para quem se reportam quando querem refletir suas práticas, avaliar seus atos.

O estresse, realmente, leva você a não prestar uma assistência digna para o paciente, porque quando você está estressada, você não mede... É... até para responder a uma pergunta que a pessoa está fazendo, você responde com agressividade, quer dizer, não dá uma boa assistência, isso aí realmente é muito chato. (Enfa 02)

[...] Eu lembro que, no início, eu via o paciente mais, assim, como um robô, muito automático, até eu tentar humanizar mais essa assistência levou um tempo para eu tomar essa consciência de que precisava mudar, não é? E para que tivesse essa mudança, eu preciso fazer terapia para me ajudar, muitas pessoas, talvez, não consigam perceber, outras, talvez, por si só vençam os obstáculos. Eu acho importante esse cuidar ser mais humanizado e uma das coisas que me fez procurar a terapia foi isso, essa robotização da assistência de enfermagem é grave, os profissionais ficam como um robô pelo acúmulo de trabalho, não é? Então, isso, eu acho muito grave, a sobrecarga de trabalho. No robô você fica mecânica, faz um cuidado sem pensar, sem refletir, você começa a não pensar mais, faz rotinas sem pensar e, isso, é muito, eu acho que para a enfermagem, isso é muito grave, porque você está lidando com vidas, gente que tem sensibilidade, que observa, então isso é uma coisa que me assustou muito quando eu me percebi como um robô, fazendo as coisas sem pensar, sem pensar, sem refletir, não é? Pelo acúmulo de serviços, se você não tiver cuidado, você fica um robô, eu acho, o auxiliar, o enfermeiro, nós profissionais ficamos muito mecânicos, fazendo as coisas sem pensar, sem emoção. Fica uma coisa mecânica mesmo, é como se você não tivesse lidando com gente e gente tem sensibilidade. [...] (Enfa 05) 
Fernandes SMBA, Medeiros SM, Ribeiro LM. Estresse ocupacional e o mundo do trabalho atual: repercussões na vida cotidiana das enfermeiras. Revista Eletrônica de Enfermagem [Internet]. 2008;10(2):414-427. Available from: http://www.fen.ufg. br/revista/v10/n2/v10n2a13.htm

É oportuno trazer para discussão a defesa contra o sofrimento pautada no ativismo, ou seja, o engajamento na ação, a realização do trabalho até a exaustão, lembrando que o objetivo nesse caso é não pensar mais, não refletir mais e mesmo não mais perceber o sofrimento ${ }^{(15)}$. De alguma forma isso está posto no trabalho da enfermagem, quando o trabalhador executa as atividades sem pensar, muito centrado no fazer. A rotina toma conta da vida dos trabalhadores, como se constata na fala da Enfa 05, a indiferença e a falta de sensibilidade no trato com os pacientes pode se manifestar. O trabalhador passa a desempenhar atividades não pensadas e automatizadas que o conduz a um estado de alienação. Todas essas questões abordadas neste item precisam ser analisadas considerando a opção dessas enfermeiras pelo aumento de suas jornadas de trabalho e complementação salarial: o cenário e as falas advindas do mundo do trabalho atual, no qual o trabalho em saúde e em enfermagem encontra-se inserido.

\section{CONSI DERAÇÕES FI NAIS}

Considerando os objetivos do presente estudo, constata-se que as condições de trabalho às quais estão expostas as trabalhadoras pesquisadas, favorecem a exposição dessas trabalhadoras ao estresse ocupacional, em primeiro lugar, pelas características inerentes à profissão, segundo, porque para além da natureza do trabalho, há que se considerar a forma precarizada desse trabalho vivenciado por essas trabalhadoras, que embora mantendo um vínculo formal, atuam com escalas extras de jornada de trabalho, essas sim, caracterizadas como trabalho precarizado dentro do vínculo de trabalho formal, realidade essa já identificada anteriormente no estudo de Veras ${ }^{(19)}$.

Essas trabalhadoras, vivenciando um cenário de instabilidade e insegurança e tendo ainda de conviver com a ausência de horas adequadas de repouso e, simultaneamente, com a falta de tempo para a realização de outras atividades heterogêneas do cotidiano, acabam por desenvolver o estresse ocupacional, muitas vezes com sofrimento e adoecimento, como apontado pelos resultados do presente estudo.

Portanto, acredita-se que estudar as repercussões do estresse ocupacional na vida cotidiana de enfermeiros é a melhor forma de compreender as matizes e nuanças que interferem e determinam esse fenômeno, assim como a ressonância produzida por ele na vida cotidiana desses trabalhadores. Acredita-se ainda que ao se apreender e compreender esse fenômeno através dos relatos dos atores sociais verdadeiramente implicados, por vivenciá-lo no dia-a-dia do seu processo de trabalho, pode-se buscar mudanças e traçar novas formas de condução dessa questão.

Conclui-se que o estresse ocupacional decorrente de um processo de trabalho marcado por condições precárias de trabalho e pelo aumento de jornada de trabalho, tem fortes repercussões no cotidiano profissional e pessoal das enfermeiras entrevistadas.

Acredita-se que não se pode fazer um manejo do estresse ocupacional sem levar em conta as características estruturais da realidade sócio-econômica do país e do mundo, que submete os trabalhadores a uma condição concreta referente ao mundo do trabalho atual, condição a qual todos os trabalhadores estão submetidos. Desse modo, entende-se como primordial e anterior à proposição de saídas, a compreensão da influência da realidade sócioeconômica e do contexto organizacional na determinação do fenômeno estresse ocupacional, assim como a compreensão das repercussões acarretadas por esse fenômeno na vida cotidiana do profissional enfermeiro, tendo sido esse o objetivo do presente estudo.

\section{REFERÊNCI AS}

1. Codo W. Educação: carinho e trabalho. Petrópolis (RJ): Vozes; 1999.

2. Stacciarini JMR, Tróccoli BT. Estresse Ocupacional. In: Mendes AM, Borges LO, Ferreira, MC (Orgs.). Trabalho em transição, saúde em risco. Brasília: Universidade de Brasília; 2002. p. 187-205.

3. Guido LA. Stress e coping entre enfermeiros de centro cirúrgico e recuperação anestésica [tese]. [São Paulo]: Escola de Enfermagem, Universidade de São Paulo; 2003. 
4. Bianchi ERF. Stress entre enfermeiros hospitalares [livre docência]. [São Paulo]: Escola de Enfermagem, Universidade de São Paulo; 1999.

5. Minayo MCS. O Desafio do conhecimento: pesquisa qualitativa em saúde. São Paulo/Rio de Janeiro: Hucitec-Abrasco; 1998.

6. Meihy JCSB. Manual de História Oral. $4^{a}$ edição. São Paulo: Loyola; 2002.

7. Triviños ANS. Introdução à pesquisa em ciências sociais: a pesquisa qualitativa em educação. São Paulo: Atlas; 1987.

8. Stacciarini JMR, Tróccoli BT. O estresse na atividade ocupacional do enfermeiro. Revista Latino Americana de Enfermagem. 2001; 9(2): 17-25.

9. Gomes ELR, Anselmi ML, Mishima SM, Villa TCS, Pinto IC, Almeida MCP. Dimensão histórica da gênese e incorporação do saber administrativo na enfermagem. In: Almeida MCP, Rocha SMM, org. O Trabalho de Enfermagem. São Paulo: Cortez; 1997. p. 229250.

10.Wisner A. Por dentro do trabalho: ergonomia: método \& técnica. São Paulo: FTD: Oboré; 1987.

11. Almeida PJS, Pires DEP. O trabalho em emergência: entre o prazer e o sofrimento. Revista Eletrônica de Enfermagem [Internet]. 2007 [cited 2007 mai 24];9(3):617-629. Available from: http://www.fen.ufg.br/revista/v9/n3/v9n3a05.h $\underline{\mathrm{tm}}$.

12. Veras VSD. Aumento da jornada de trabalho: qual a repercussão na vida dos trabalhadores da enfermagem? [dissertação]. [Natal]: Programa de Pós-graduação em Enfermagem/Universidade Federal do Rio Grande do Norte; 2003.

13. Medeiros SM, Ribiero LM, Fernandes SMBA, Veras VSD. Condições de trabalho e enfermagem: a transversalidade do sofrimento no cotidiano. Revista Eletrônica de Enfermagem [Internet]. 2006 [cited 2007 mai 24];8(2):233240. Available

from: http://www.fen.ufg. br/revista/revista8_2/v8n2a 08.htm.

14. Medeiros SM. As novas formas de organização do trabalho na terceira revolução industrial e a força de trabalho em saúde: estudo em Natal/RN [tese]. [Ribeirão Preto]: Escola de Enfermagem/USP; 2000.

15. Averdaño C, Grau P, Yus P. Riscos para a saúde das enfermeiras do setor público no Chile. In: Oliveira EM, Scavone L, orgs. Trabalho, saúde e gênero na era da globalização. Goiânia: AB; 1997.

16. Dejours C. A loucura do trabalho: estudo de psicopatologia do trabalho. $5^{a}$ edição. São Paulo: Cortez-Oboré; 1992.

17. Pafaro RC, Martino MMF. Estudo do estresse do enfermeiro com dupla jornada de trabalho em um hospital de oncologia pediátrica de Campinas. Revista da escola de enfermagem da USP. 2004; 38(2): 152-160.

18. Manetti ML, Marziale MHP. Fatores associados à depressão relacionada ao trabalho de enfermagem. Estudos de Psicologia. 2007; 12(1): 79-85.

19. Heller A. O Cotidiano e a História. São Paulo: Paz e Terra; 2000.

20. Antunes R. Os sentidos do trabalho: ensaios sobre a afirmação e a negação do trabalho. $5^{\text {a }}$ edição. São Paulo: Bontempo; 2001.

Artigo recebido em 17.03.07

Aprovado para publicação em 30.06.08 